\title{
Measurement based robot cutting as preparation for welding tubular connections
}

\author{
Sascha Lauer ${ }^{1}$, Tina Ambrosat ${ }^{1}$, Martin-Christoph Wanner ${ }^{1}$, Wilko Flügge ${ }^{1,2}$ \\ ${ }^{1}$ Fraunhofer Research Institution of Large Structures in Production Engineering IGP, Albert- \\ Einstein-Straße 30, 18059 Rostock, Germany \\ ${ }^{2}$ Chair of Production Technology, University of Rostock, Albert-Einstein-Straße 2, 18059 Ros- \\ tock, Germany \\ \{sascha.lauer, tina.ambrosat, martin-christoph.wanner, \\ wilko.fluegge\} @igp.fraunhofer. de
}

\begin{abstract}
In the production of offshore tubular connections, the cutting process is an important factor. Undefined root gaps between the individual pipe connections require time-consuming reworking and increased welding effort, resulting in longer production times and higher costs. The developed procedure is based on the $3 \mathrm{D}$ measurement of the pipes in order to consider the real geometries in the planning of the cutting process and to optimize the following joining process by adapting the root gap all over the tubular connection and to get a constant seam cross section. The basic concept is to build the planned connection virtually with the measured and real pipe geometries and to plan the flame cutting process including weld seam preparation on the base of the result. For the measurement in the production environment, a suitable measuring concept was developed to return the results directly into the cutting process with the robot. This is the base for the automation of the tubular connection production.
\end{abstract}

Keywords: offshore structures, sensor-based programming, path planning, robotic cutting

\section{Introduction}

Jacket structures play an important role in offshore technology. They are used as foundation for converter platforms at sea as well as for wind energy plants. Jackets are complex tubular connections based on pipes (Fig. 1). Compared to other offshore foundation structures, the used pipes have smaller diameters and material thicknesses. Accordingly, jackets can be produced with lower material costs than comparable structures with similar functions, such as monopiles. However, the complexity results in higher production costs. An essential cost driver are the deviations in the pipe production, resulting with time-consuming and cost-intensive manual rework in the assembly. 

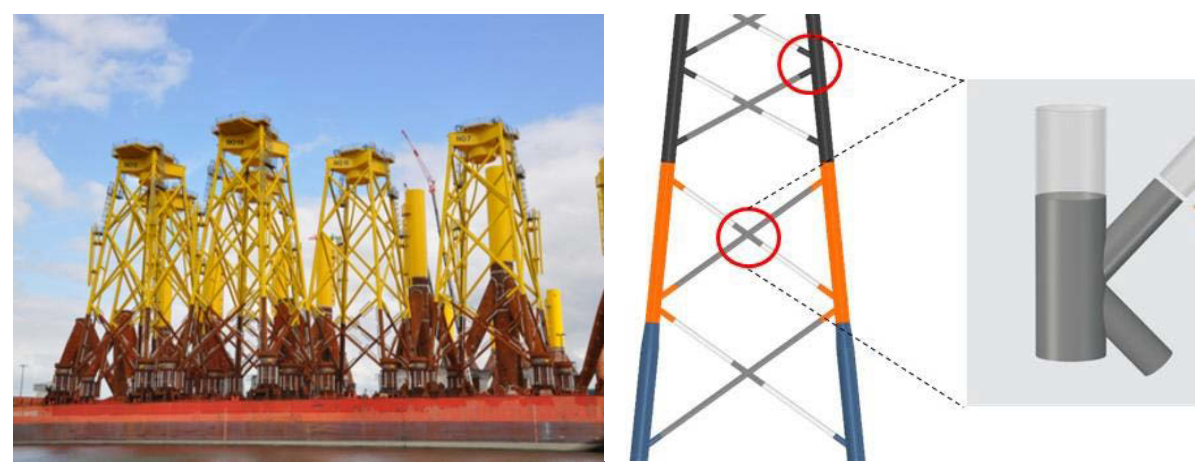

Fig. 1. Jacket structure (left), tubular connection (right) [1]

The main reason for the need for reworking was identified as the determination of the cutting contours without taking into account the production deviations of the real pipes. By measuring the real tube geometries and by not using the CAD geometry, the manufacturing process for joining the tubular connections is to be adapted in order to minimize manual reworking and thus reduce manufacturing costs.

Fig. 2 shows the manufacturing process of a tubular connection as a process chain. The process adapts the cutting process to the tolerances in pipe production and serves as the basis for positioning and joining the pipe.

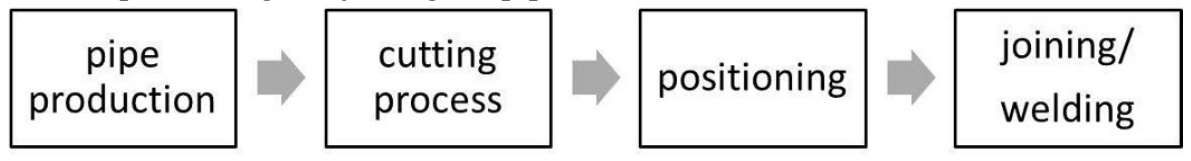

Fig. 2. Process chain for tubular connection production

Tubular connections consist of a main member pipe and one or more branch member pipes (see Fig. 3), whereby the pipe diameters used here varied from $500 \mathrm{~mm}$ to $3000 \mathrm{~mm}$ and the material thicknesses between $20 \mathrm{~mm}$ and $120 \mathrm{~mm}$.

By flame cutting, the pipe of the branch member is prepared for the joining process. The contour which is calculated by virtually placing the branch member pipe on the main member pipe is based on the ideal geometries of both pipes. In addition, the weld seam preparation is planned for the branch member pipe by using this contour. For conforming the standards of joining for this tubular connection it requires a defined root gap between 2 and $8 \mathrm{~mm}$ [2], which depends on the different zones over the various areas of the weld (see I, II and III in Fig. 3). 


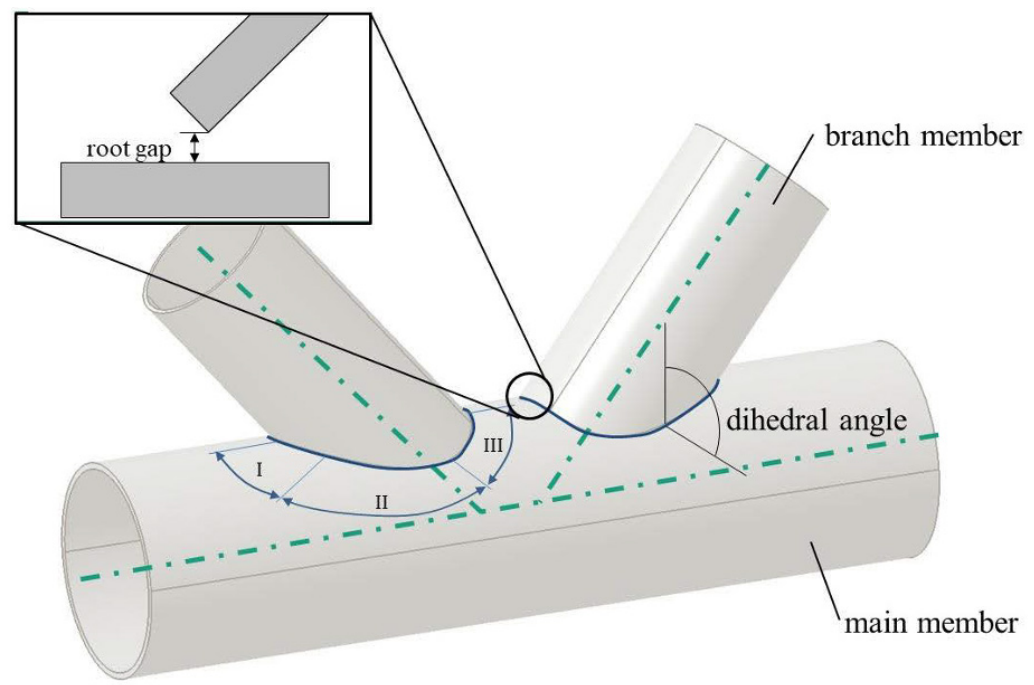

Fig. 3. K-connection with definitions of root gap, dihedral angle (opening angle between surfaces) and the zones (I - heel zone; II - side zone; III - toe zone)

Due to the production deviation of both pipes, the ideal seam course in the pipe joint must be adapted to reality. If this is not the case, the joining technology will not be able to tolerate root gaps, which will lead to serious manual reworking such as grinding of the weld in the cut surface. The conventional manufacturing of tubular connections doesn't consider the real geometries of the main member pipe during weld seam preparation. Only the real pipe geometry of the branch member is used to ensure the quality of the cut.

By planning the contour based on real pipe geometries and by generating constant seam cross sections in the weld seam preparation, automated welding with the specially developed orbital welding system in high quality is possible [3].

\section{Description of the developed process}

In order to achieve these goals, the manufacturing process has to be adapted and the measurement of the pipes integrated into it. Specifically, the following steps (Fig. 4) are necessary:

- Recording the geometry of the main and the branch member

- Determination of the virtual cutting contour

- Inclusion of weld seam preparation

- Flame cutting of the pipe with a robot

Compared to the state of the art, the first two steps reduce the expensive and timeconsuming re-working by a slightly increasing production planning. 


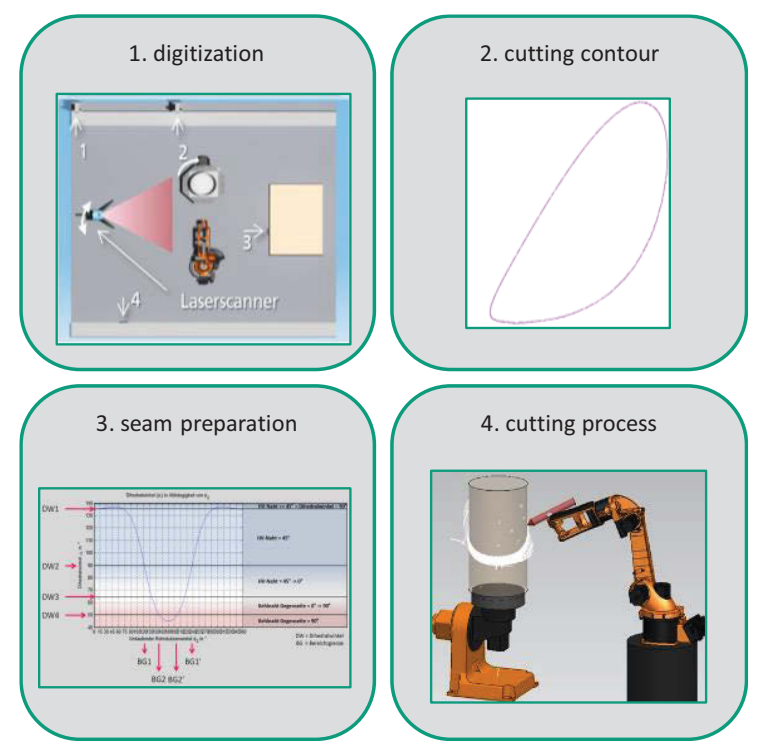

Fig. 4. Process steps for cutting with robots

In the following, the mentioned four steps are examined using an example tubular connection. In the selected configuration, a branch member pipe with a diameter of $508 \mathrm{~mm}$ and a material thickness of $20 \mathrm{~mm}$ is placed centrally at an angle of $45^{\circ}$ on the main member pipe with a diameter of $1016 \mathrm{~mm}$.

\section{$2.1 \quad$ Test setup}

For the execution of tests, a suitable plant design was developed. A welding robot (KUKA kr5 arc) in combination with a turn and tilt positioner (KUKA DKP400) is used to extend the working area of the robot. The positioner can handle pipes up to a mass of $400 \mathrm{~kg}$, which is necessary for the chosen branch member pipe.

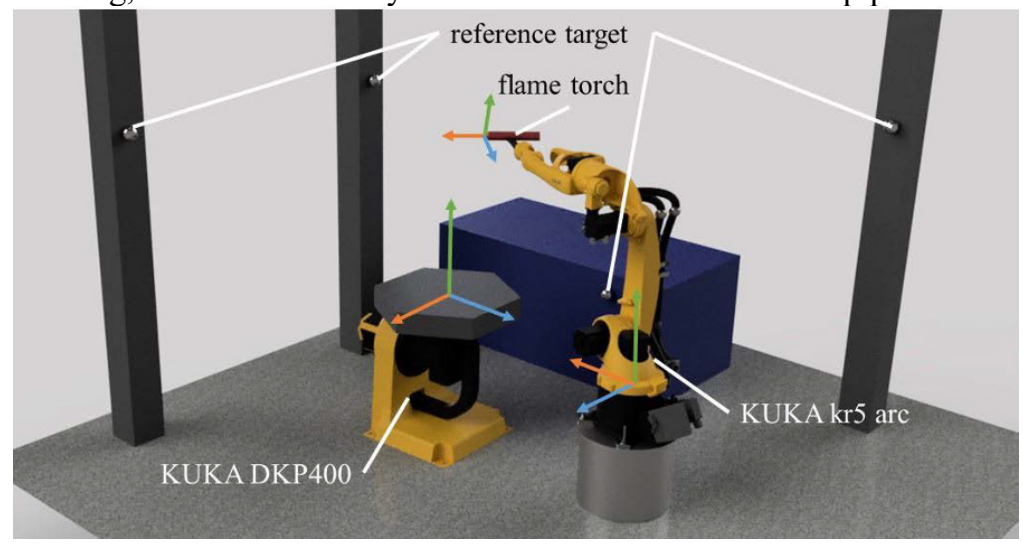

Fig. 5. Test setup for the robot cutting 
In order to work with the highest accuracy during the entire process, the coordinate systems of the tilt and turn positioner and the robot were measured to each other using an external measuring system (laser tracker). After the robot system was measured, it was referenced to a selected global system defined by reference marks. This is used throughout the process.

\subsection{Digitization of the pipes}

Both pipes are digitized in the production environment by a laser scanner. The used $\mathrm{Z}+\mathrm{F}$ IMAGER ${ }^{\circledR} 5010$ has a linearity error of less than $1 \mathrm{~mm}$ and a distance noise of $0.5 \mathrm{~mm}$ rms at 10 meter [4]. Distances of more than 10 meter to the measuring object are not provided for in the measuring concept.

The main member pipe is measured horizontally. The coordinate system is defined by the pipe axis, flange plane and a marking of the theoretical intersection point of the pipe axis with the pipe surface.

When measuring the branch member pipe, it is perpendicular to the tilt and turn positioner. The robot has a pose repeatability of $\pm 0.06 \mathrm{~mm}$ [5], which is used throughout the process. Instead of measuring the tube from different angles and positions, only one laser scanner position is required and the pipe is rotated between each scan using the tilt and turn positioner (see Fig. 6). The registration of the scans takes place in the coordinate system of the tilt and turn positioner, defined by the rotary axis of the table and a rotary angle. The generated point clouds of the outer surface of the branch member pipe are assembled in the evaluation software by turning them back about the defined rotary angle of the positioner. Due to the overlapping areas of the various scans and the unfavorable impact angle of the laser, data smoothing is necessary.

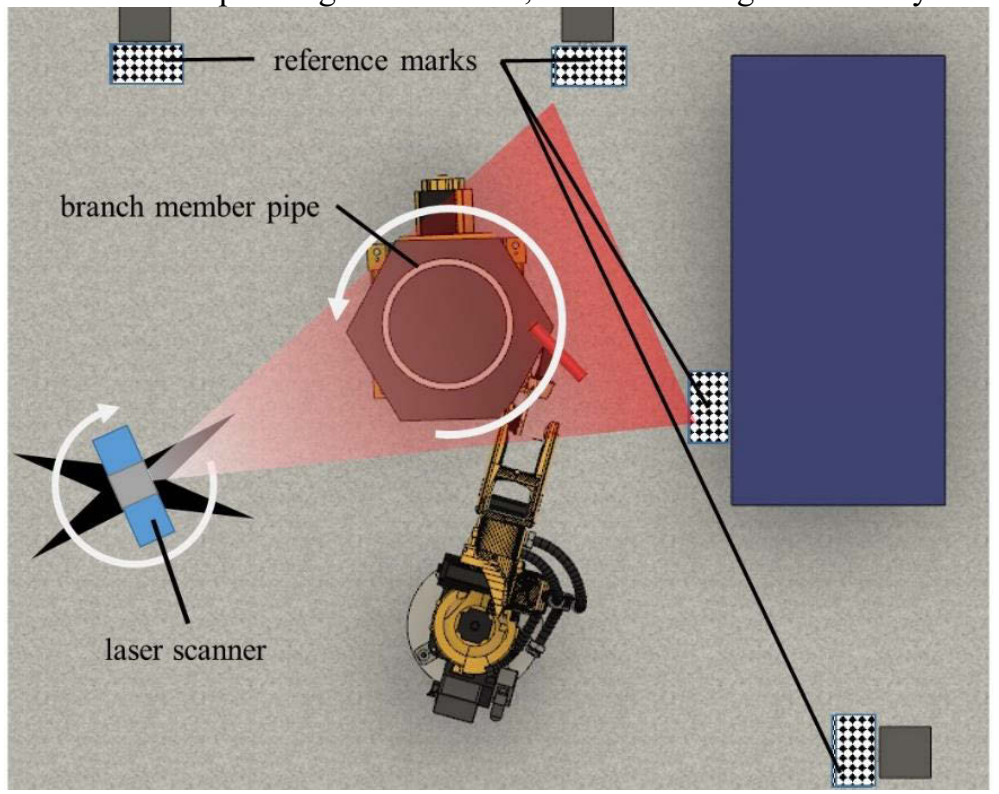

Fig. 6. Measuring setup for the measurement of the branch member pipe 
A measurement of the branch member pipe from the inside does not take place, since the effort seems inappropriate due to the inner diameter and difficult referencing. During preparatory measurements of the pipe geometries, it was determined that the material thicknesses of the pipes, with the exception of the weld seam, is approximately constant. Therefore, the data points of the inner pipe surface are simulated on the base of the data points of the outer pipe surface using the pipe axis determined by cylinder segmentation according to [6]. The planned configuration is now virtually simulated with the point clouds of the main member pipe and the branch member. The axis of branch member pipe is transformed to the z-axis and the axis of the main member pipe is aligned at the defined angle (see Fig. 7 (left)). The breakthrough point of the z-axis on the surface of the main member pipe is known from the measurement concept. By translating the point cloud parallel to the pipe axis, the dimensions of the future socket are virtually taken into account.
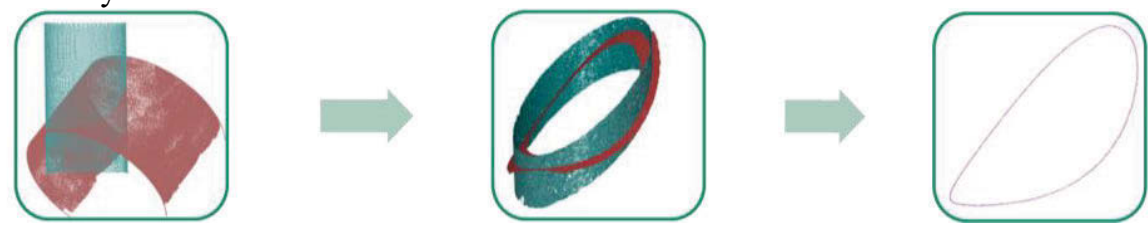

Fig. 7. Process flow for determining the virtual intersection contour using the example of the outer surface of the extension tube, virtual alignment (left), polygonised intersection areas (center) and intersection contour (right)

Using trigonometric methods, the intersection areas of the point clouds were identified on the base of the configuration and the points lying within them were polygonised (see Fig. 7 (center)). From the calculation of the section of the polygonised areas, a 3D polyline is obtained, with a $\mathrm{C}^{3}$ continuous, closed BSpline curve approximated by its straight line center points (see Fig. 7 (right)). The results are the curves (inner and outer contour), in which point cloud of the main member pipe crosses the point cloud of the branch member pipe. The outer curve corresponds to the seam contour (see Fig. 3), on which the weld seam preparation takes place.

\subsection{Weld seam preparation}

The dihedral angle is used to determine the seam course [2]. Fig. 8 shows a seam course corresponding to the standard for the production of a pipe joint with the used configuration. If the dihedral angle is smaller than $50^{\circ}$, a fillet weld is prepared (zone I, Fig. 3), if it is larger than $90^{\circ}$, a bevel groove is prepared (zone III, Fig. 3). The area in between is called the transition area (zone II, Fig. 3), because the change between these two seam types takes place. The course of this seam was defined in such a way that it can be flame cut with a single move. The challenge is that the seam opening angles which needs to be cut becomes acute. For later use, this step has to be adapted to a two-part cut. 


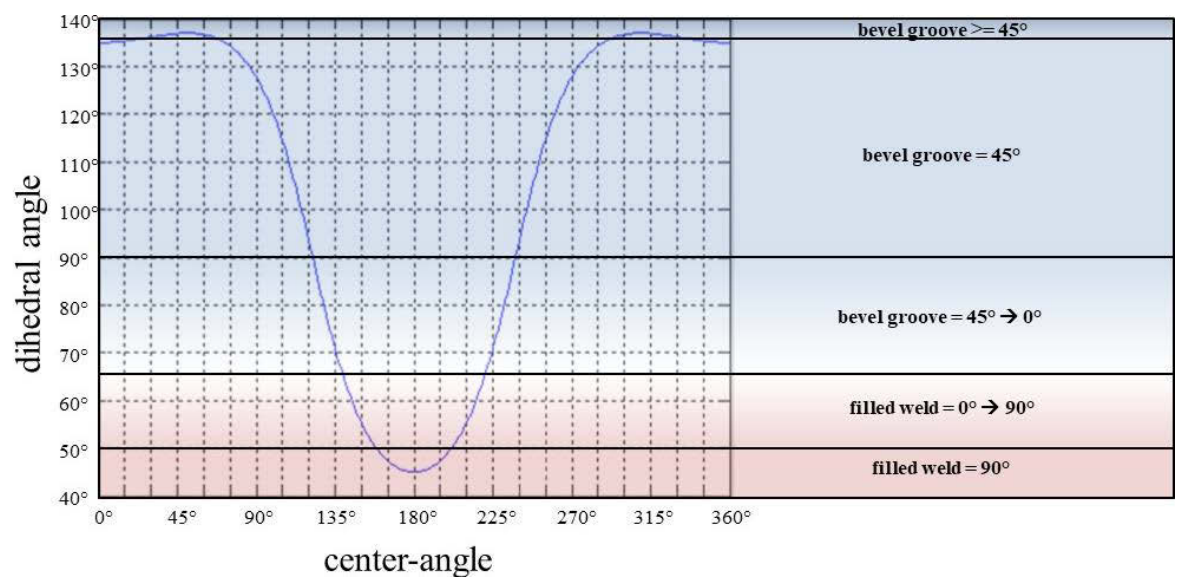

Fig. 8. Seam definition in the selected configuration, depending on the dihedral angle

The shown dihedral angles were determined with the seam contour of an ideal tubular connection with faultlessly pipes. In case of a fillet weld, the main member pipe and the branch member pipe touch each other at the outer contour. In case of a bevel groove, the inner contour of the branch member pipe is in contact.

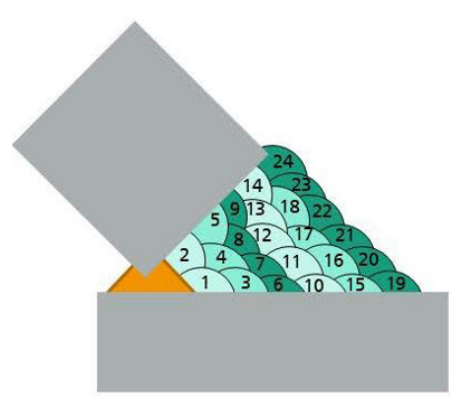

bevel groove

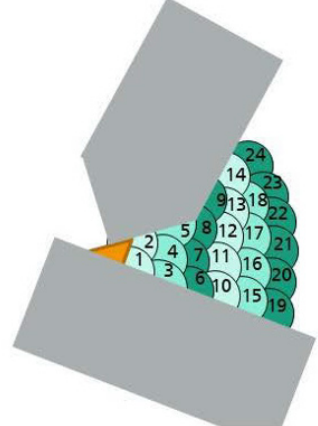

transition area

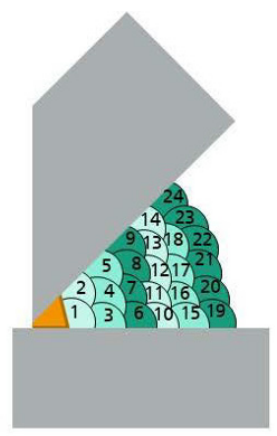

fillet weld

Fig. 9. Target layer structure for tubular connection at different areas (branch member - top, main member - bottom)

The necessity of an accurately planned cut and the contact between both pipes is shown in Fig. 9. For a future automated welding process, with the aim of achieving a uniform layer structure, it is essential to achieve a constant root gap and a defined weld cross section. Otherwise, the welding parameter has to be adjusted during the entire joining process.

\subsection{Offline programming and Preparation for flame cutting}

Since the flame cut is placed on the outer surface of the branch member pipe, the calculated points for the robot have to be shifted to the outer surface of the branch member 
pipe along the cutting direction (see Fig. 10 (left)). For a constant cutting quality, the torch distance to the cutting surface has to be constant. This is achieved by further shifting each point along the corresponding cutting direction by an offset. A retransformation of the data provides the discrete positions and directions of the torch head in the coordinate system of the tilt and turn positioner. The robot is integrated in this coordinate system. Since the tilt-turn positioner has a higher accuracy than the robot, the turntable rotates during the cutting process, while the robot only performs small movements. The robot software interpolates between the position and direction data and calculates the positions of the axis in order to avoid singularity positions. By using synchronized movements from the positioner and the robot, it is possible to cut at constant speed using all eight axes.
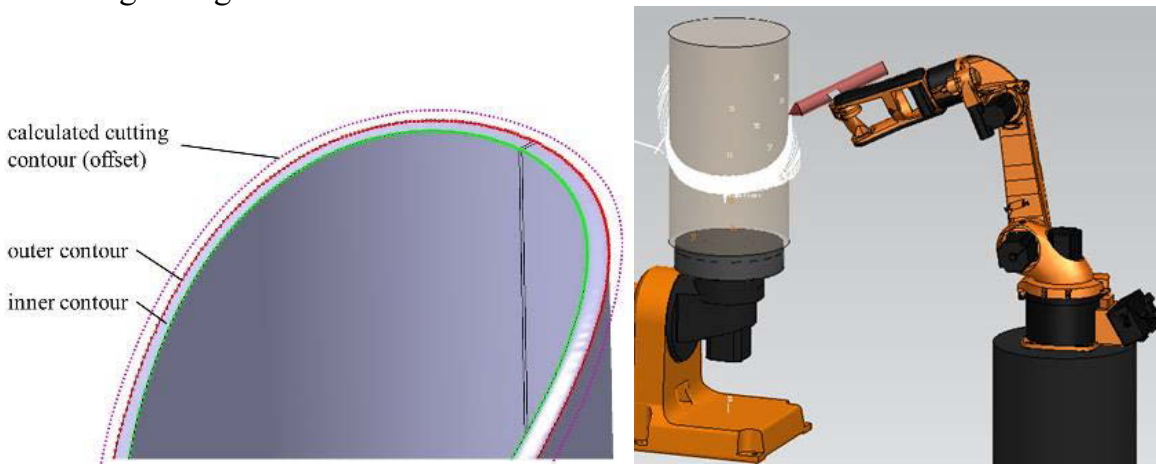

Fig. 10. Calculated contour (left) and path planning with the robot in SIEMENS RobotExpert (right)

This is the base for the offline-programming of robot motion (see Fig. 10, right) and collision control to prevent crashes between the robot/torch and the pipe. In addition, motion commands and switching commands for the cutting process, such as start and stop distances, ignition commands and waiting times, have to be added.

\section{$3 \quad$ Verification and Results}

The method is used to manufacture the described tubular connection. The cut branch member pipe, especially the cut surface, is measured with the strip light projection system GOM Atos Triple Scan. A $300 \times 300 \mathrm{~mm}^{2}$ measuring field is used, with which a measuring accuracy of approx. $0.01 \mathrm{~mm}$ can be achieved [7].

First of all the resulting model is compared with an ideal cylinder to determine the production deviations. On the other hand, the model is virtually placed on the digitized main member pipe in the defined configuration and aligned by best-fit method, whereby only rotation around and displacement along the pipe axis are permitted. The root gap can be derived from this. The results are shown in the form of a measurement in Fig. 11. 

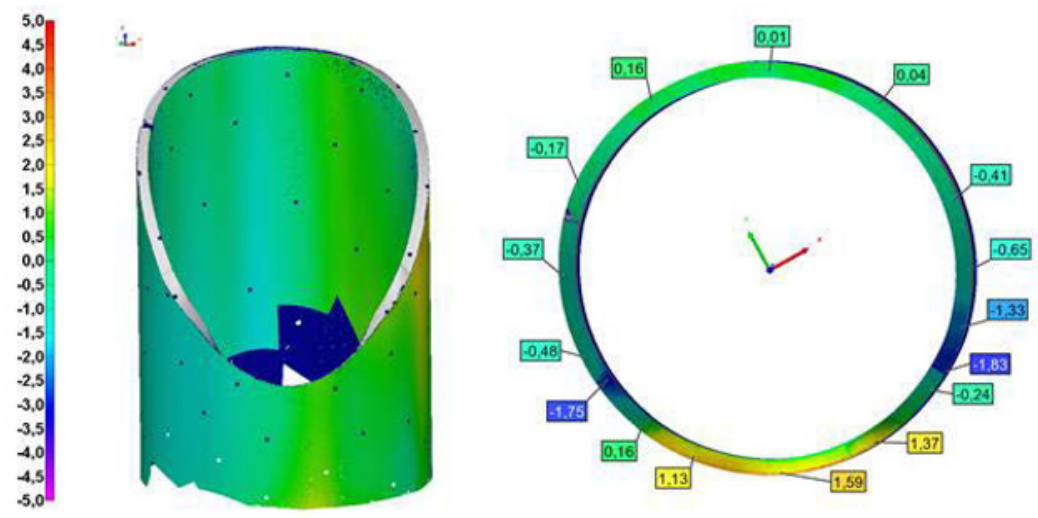

Fig. 11. Measurement results to illustrate the production deviations of an extension tube (left) and to illustrate the deviation of the cut surface from the planned one (right).

The production deviations of the attachment pipe are clearly visible in the left measurement. The tolerance of $\pm 5 \mathrm{~mm}$ is maintained [8]. The right measurement shows the deviations between the virtually planned and the actual cut surface. The maximum deviation, this means the largest gap between both pipes, is $1.59 \mathrm{~mm}$. The minimum deviation, the largest penetration of the two pipes, is $-1.83 \mathrm{~mm}$. They vary by $3.42 \mathrm{~mm}$. Within the bevel groove area (zone III, Fig. 3, upper cut area, Fig. 11) the deviations differ by less than $1 \mathrm{~mm}$. Within the fillet weld area (zone I, Fig. 3, lower cut area, Fig. 11), too. The variations in the transition areas are more than $2 \mathrm{~mm}$. The specified fluctuations of the nominal root gap of $6 \mathrm{~mm}$ are adhered to. Despite the production deviations, the weld seam can be prepared in accordance with the standards.

\section{Conclusion and outlook}

It has been proven that the interaction of measurement technology, cutting contour planning and robot cutting can be successfully applied in practice. Both the tubular connection configuration and the selected seam configuration are to be understood as an example. The process can be used for any tubular connection and seam configuration. Further optimization possibilities are in the next process steps of positioning and joining (see Fig. 2). The challenge in positioning is that the approach point planned in the configuration, in which the branch member pipe axis meets the axis of the main member pipe, is calculated and has to be transferred to the real pipe configuration.

In order to optimize the joining process, based on a two-part cut, a suitable seam configuration can be developed. Because the seam course is planned and implemented on the base of the actual data, virtual weld layer planning is possible without further measurement, which additionally accelerates the production process. In particular, this enables automation of the welding process. 


\section{References}

1. Brauser, S, Lauer, S.: Mechanisierung eines Mehrlagenschweißprozesses zum Fügen von Offshore-Rohrverbindungen, 8. Zukunftskonferenz: Wind \& Maritim, Rostock 2019

2. American Welding Society: AWS D1.1:Structural Welding Code-Steel, Miami (2000)

3. Herholz, H., Dryba, S., Gründler, M., Wanner, M.-C.: Development of a flexible special kinematics for fully mechanized production of tubular nodes for offshore foundation structures. In: Tagungsband des 2. Kongresses Montage Handhabung Industrieroboter, pp. 1-11. Springer, Heidelberg (2017)

4. Zoller + Fröhlich GmbH, Z+F IMAGER 5010 Datenblatt, Bridgewille:Z+F USA

5. KUKA Roboter GmbH, KUKA Positionierer DKP-400, DKP-400 endlos Spezifikation, Augsburg 2013

6. Rusu, R. B., Cousins,S.: 3D is here: Point Cloud Library (PCL), Menlo Park 2011

7. GOM GmbH, Atos Triple Scan - Industrieller optischer 3D-Digitalisierer, Braunschweig 2017

8. Deutsches Institut für Normung: DIN EN 10216-1:2014-03 Nahtlose Stahlrohre für Druckbeanspruchungen - Technische Lieferbedingungen - Teil 1:Rohre aus unlegierten Stählen mit festgelegten Eigenschaften bei Raumtemperatur, Beuth Verlag 2014

9. Ambrosat,T., Lauer,S., Geist,M. Flügge,W.:Bestimmung komplexer Schneidkonturen als Vorbereitung zum Verschweißen von 3D Rohrstößen, GFaI, Berlin 2018

Open Access This chapter is licensed under the terms of the Creative Commons Attribution 4.0 International License (http://creativecommons.org/licenses/by/4.0/), which permits use, sharing, adaptation, distribution and reproduction in any medium or format, as long as you give appropriate credit to the original author(s) and the source, provide a link to the Creative Commons license and indicate if changes were made.

The images or other third party material in this chapter are included in the chapter's Creative Commons license, unless indicated otherwise in a credit line to the material. If material is not included in the chapter's Creative Commons license and your intended use is not permitted by statutory regulation or exceeds the permitted use, you will need to obtain permission directly from the copyright holder.

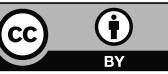

